\title{
High-resolution sedimentary records of some organochlorine pesticides in Yamzho Yumco Lake of the Tibetan Plateau: Concentration and composition
}

\author{
Yong Sun ${ }^{\mathrm{a}, \mathrm{b}}$, Guo-Li Yuan ${ }^{\mathrm{a}, \mathrm{b}, *}$, Jun Li $^{\mathrm{b}}$, Jianhui Tang ${ }^{\mathrm{c}}$, Gen-Hou Wang ${ }^{\mathrm{b}}$ \\ a State Key Laboratory of Biogeology and Environmental Geology, China University of Geosciences, Beijing 100083, China \\ b School of the Earth Sciences and Resources, China University of Geosciences, Beijing 100083, China \\ ${ }^{c}$ Key Laboratory of Coastal Environmental Processes and Ecological Remediation, Yantai Institute of Coastal Zone Research, Chinese Academy of Sciences, Yantai 264003, China
}

\section{H I G H L I G H T S}

- Sediment cores of Yamzho Yumco Lake were dated with high-resolution.

- OCPs peaks in the core induced by melting glaciers or the cryosphere were found.

- The weak degradation after deposition in the lake preserves the historical record.

- Some neglected OCPs in the Tibetan Plateau were also detected for the first time.

\section{A R T I C L E I N F O}

\section{Article history:}

Received 23 July 2017

Received in revised form 25 September 2017

Accepted 26 September 2017

Available online 5 October 2017

Editor: Jay Gan

\section{Keywords:}

Organochlorine pesticides

Sediment cores

High-resolution dating

Glacial melting

Global warming
GRA P H ICA L A B S T R A C T

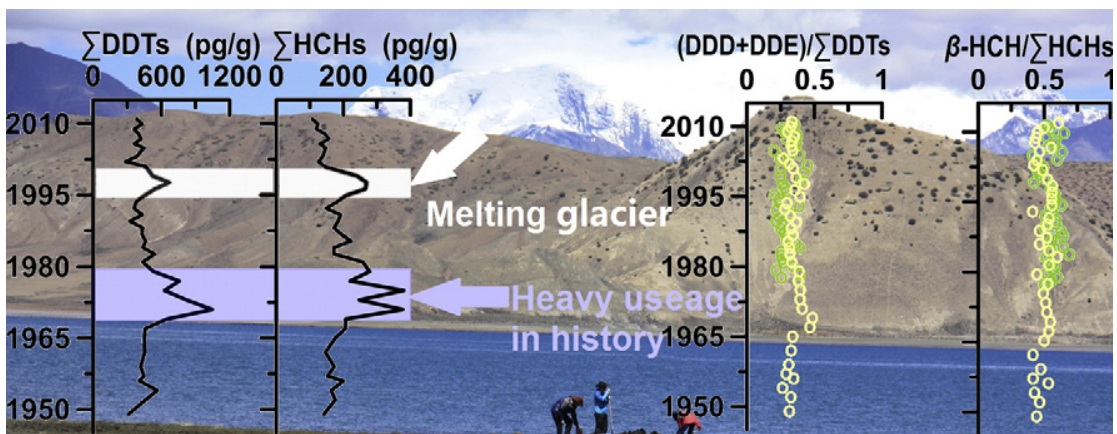

\section{A B S T R A C T}

Sediment cores from lakes have been used to reconstruct the historic deposition of persistent organic pollutants (POPs), especially in remote alpine areas. To reconstruct the deposition history of organochlorine pesticides (OCPs) in the Tibetan Plateau (TP), two sediment cores from Yamzho Yumco Lake were drilled and dated with high-resolution, from which 23 OCPs were analyzed in greater detail. Regarding several legacy compounds, concentration peaks in the cores were observed in the 1970s, corresponding to the heavy usage of these compounds around the world. In addition, another peak was found at the end of the 1990s, which was explained as the addition of OCPs released from melting glaciers or the cryosphere due to global warming. Furthermore, it was found that the transformation or degradation of OCPs after deposition in the lake was limited by comparing the values of isomeric ratios at different times, such as (DDD + DDE)/ $/$ DDTs, o, $p^{\prime}-\mathrm{DDT} / p, p^{\prime}-\mathrm{DDT}$ and $\beta-\mathrm{HCH} / \sum \mathrm{HCHs}$. Such results ensure that the detected OCPs in the lake sediments really reflect their characteristics at the time of deposition. On the other hand, weak environmental self-purification of the OCPs made them last longer in the TP than in other regions. Reasonably, the fragile ecological environment of the TP would be threatened not only by legacy POPs that remain in the sediments and soils but also by POPs released from melting glaciers or the cryosphere in the next few decades under the influence of global warming. Our research provides an insight into the influence of global warming and glacial melting on the environment of the TP, and further work to gain a better understanding of the environmental processes of POPs in the TP is ongoing.

(C) 2017 Elsevier B.V. All rights reserved.

\footnotetext{
* Corresponding author at: State Key Laboratory of Biogeology and Environmental Geology, China University of Geosciences, Beijing 100083, China. E-mail address: yuangl@cugb.edu.cn (G.-L. Yuan).
} 


\section{Introduction}

Through long-range atmospheric transport (LRAT), persistent organic pollutants (POPs) have been detected worldwide (Shen et al., 2013), including the remote regions at high latitudes (Khairy et al., 2016; Mangano et al., 2017) and high altitudes (Wania and Westgate, 2008; Arellano et al., 2011). Sediments from lakes could effectively record the occurrence and accumulation of POPs in the region, especially in remote alpine lakes, and thus the sediment cores from lakes have usually been studied to reconstruct the deposition history of POPS (Cheng et al., 2014; Li et al., 2017a; Yuan et al., 2017). It is important to monitor POPs into remote ecosystems, such as lakes, which have been generally less studied compared to others aquatic systems. In addition to direct air deposition, POPs associated with certain natural emergencies have also been recorded in sediment cores. For example, substantial releases of legacy POPs from the glacial melting were found in sediment cores from lakes in the Central Pyrenees (Zaharescu et al., 2016), in the Alps (Bogdal et al., 2009; Bettinetti et al., 2011; Schmid et al., 2011), in Switzerland (Pavlova et al., 2016) and in North Canada (Lafreniere et al., 2006), which have been interpreted as the results of global warming.

The Tibetan Plateau (TP) has an area of over 2.5 million $\mathrm{km}^{2}$ with an average elevation $>4000 \mathrm{~m}$ above sea level, and it has been referred to as "the third pole of the earth" (Wang et al., 2016). Recently, much attention has been focused on POPs in the TP due to their potential threat to its pristine ecology (Cheng et al., 2014; Sun et al., 2015; Guzzella et al., 2016). POPs were mainly inputted and accumulated in the TP by "Mountain cold-trapping" during the process of LRAT (Wang et al., 2012; Gong et al., 2015; Yuan et al., 2015). In the TP, the total area of glaciers is $49,873 \mathrm{~km}^{2}$ and the total volume is $4561 \mathrm{~km}^{3}$ (Yao et al., 2007). Due to global warming, many glaciers have been continuously disappearing in the past decade (Yu et al., 2012). In the glacial ice core of the TP, some legacy organochlorine pesticides (OCPs) were detected at non-ignorable concentrations, with the highest value being $6 \mathrm{ng} / \mathrm{L}$ in the 1970s (Wang et al., 2008). The release of OCPs from melting glaciers in the TP has already been described in our previous report (Li et al., 2017b). Research on this subject in the TP is interesting and significant in the global environmental assessment of legacy POPs. In addition, Cheng et al. (2014) found recent increasing trends of OCPs in the sediments from lakes in the TP, which was hypothesized to be the result of glacial melting. As one fate, OCPs released from melting glaciers or the cryosphere would be transported into a lake with flowing water. If so, such OCPs should be recorded in the sediments of the lakes. To reveal this process in the TP, dated sediment cores having high-resolution are necessary since the time intervals of this process are uncertain.

While using the sediment cores from lakes to reconstruct the deposition history of OCPs, an important premise is that the transformation and degradation of OCPs in the historic sediments is limited. However, few reports have discussed this subject because of its complexity. Fortunately, the TP provides a unique condition for us to check this premise because of its weak microbiological activity due to its low temperature (Yuan et al., 2014a). Before being deposited in the TP, OCPs had undergone LRAT and great weathering (Wang et al., 2012). Such a fractionating process would make the composition of compounds tend to be uniform (Kallenborn et al., 2013). As a result, the specific ratios of compounds would help us to evaluate the transformation and degradation of OCPs in the sediment cores from lakes in the TP.

Except for dichlorodiphenyltrichloroethanes (DDTs) and hexachlorocyclohexanes (HCHs), some other compounds of OCPs, such as chlordane, mirex, chlorpyrifos and trifluralin, were also listed in the Stockholm Convention. Compared with DDTs and HCHs, these compounds were historically used in small amounts. Therefore, it is interesting to determine whether these OCPs could be detected in the TP. If they were, it would also be interesting to reveal their deposition history and to compare them with those of the DDTs and HCHs.
Yamzho Yumco Lake is a typical glacier-fed lake without a drainage outlet. Two sediment cores from Yamzho Yumco Lake were drilled and dated with high-resolution, and then some OCPs in the sediments were analyzed in detail with aims to (1) reconstruct the deposition history of OCPs in the TP, including some OCPs with small amounts of usage in history; (2) identify the release of OCPs from melting glaciers and their occurrences in sediment cores; and (3) evaluate the transformation and degradation of OCPs in the sediment cores.

\section{Materials and methods}

\subsection{Sampling and dating}

Yamzho Yumco Lake is located in the southern area of the Tibetan Plateau and is $90 \mathrm{~km}$ from Lhasa. The lake is mainly supplied by surface runoff, which include several runoff streams from glaciers. Although many tourists come to the lake for travel, there are no large-scale developments near the lake. The sampling sites are shown in Fig. 1, and more detailed information is outlined in Table S1 (Supplementary material). The sampling sites are far away from human activities. Two sediment cores were collected in August 2012, and each sample was sectioned onsite at intervals of $0.5 \mathrm{~cm}$ from the surface layer. All samples were stored at $-20{ }^{\circ} \mathrm{C}$ until further analysis. The dating method for the cores was the same as that used in our previous report (Li et al. 2017b). In summary, the age-depth relationship for the sediment cores from the lake was established based on the analysis of ${ }^{137} \mathrm{Cs}$ and ${ }^{210} \mathrm{~Pb}$ by $\gamma$-ray spectrometry. A constant rate of supply (CRS) dating model of ${ }^{210} \mathrm{~Pb}$ and the detection of ${ }^{137} \mathrm{Cs}$ peaks respectively in 1963 and 1986 were used for the chronology calculation. For the samples collected in 2012, the surface sediment layer was assumed to have been deposited in 2012. In this research, the dating resolution for the cores is considered to be accurate to within 1-2 year intervals, which is suitable for the purpose of this study.

\subsection{Chemicals}

An analytical standard of pesticide-"Mix-13" (10 ng/ $\mu \mathrm{L}$ in cyclohexane) was purchased from Dr. Ehrenstorfer (Augsburg, Germany), containing $\alpha-\mathrm{HCH}, \beta-\mathrm{HCH}, \gamma-\mathrm{HCH}$, hexachlorobenzene (HCB), cischlordane (CC), trans-chlordane (TC), $\alpha$-endosulfan, $\beta$-endosulfan, $o, p$ '-DDE, $p, p^{\prime}$-DDE, $o, p^{\prime}$-DDD, $p, p^{\prime}$-DDD, $o, p^{\prime}$-DDT, $p, p^{\prime}$-DDT, methoxychlor and mirex. Individual analytical standards for endosulfan-sulfate, trifluralin, quintozene, pentachloroanisole, chlorpyrifos, dacthal and dicofol were supplied by Dr. Ehrenstorfer as well. Trifluralin- $\mathrm{d}_{14}$ and $\mathrm{HCH}-\mathrm{d}_{6}$ were purchased as surrogate standards from Cambridge Isotope Laboratories, and the internal standard of ${ }^{13} \mathrm{C}-\mathrm{PCB}-208$ was obtained from Dr. Ehrenstorfer. Acetone, n-hexane (purity $>99 \%$ ) and dichloromethane (DCM) were purchased from LGC Standards (Wesel, Germany). They were residue-free grade and additionally distilled in a full glass unit prior to use.

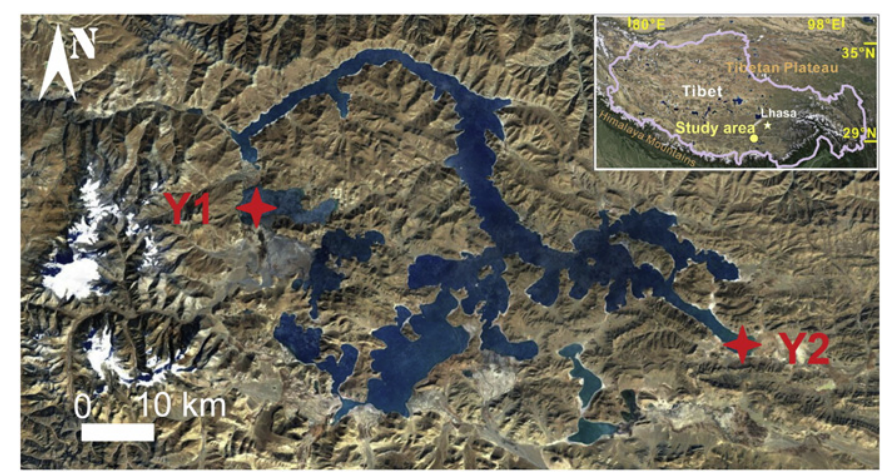

Fig. 1. Map showing the sampling-site locations of the Y1 and Y2 cores. 


\subsection{Extraction, cleanup and analysis}

Samples were freeze-dried and gently ground. Ten grams of freezedried and homogenized sediments were Soxhlet-extracted with $200 \mathrm{~mL}$ of DCM for $16 \mathrm{~h}$ and activated copper powder was used for desulfurization. Then, $500 \mathrm{pg}$ of trifluralin- $\mathrm{d}_{14}$ and $\mathrm{HCH}-\mathrm{d}_{6}$ were added as surrogates before extraction. The extracts were concentrated to $2 \mathrm{~mL}$ using a rotary evaporator and further cleaned using a $2.5 \mathrm{~g} 10 \%$ waterdeactivated silica gel (mesh size 70 to 140) column topped with $3 \mathrm{~g}$ of anhydrous granulated sodium sulfate. The column was eluted with $20 \mathrm{~mL}$ of hexane and the extracts were evaporated to a final volume of $200 \mu \mathrm{L}$. In addition, $500 \mathrm{pg}$ of ${ }^{13} \mathrm{C}-\mathrm{PCB}-208$ was added as an internal standard.

The OCPs in the samples were analyzed using a gas chromatograph (Agilent $6890 \mathrm{GC}$ ) coupled with a triple quadrupole mass spectrometer (Agilent 5973 MS) equipped with a programmed temperature vaporizer (PTV) injector (Agilent Technologies, USA) and used in the electron capture negative chemical ionization mode (ECNCI). Analytes were separated with an HP-5MS column $(30 \mathrm{~m} \times 0.25 \mathrm{~mm}$ i.d. $\times 0.25 \mu \mathrm{m}$ film thickness, J\&W Scientific). Methane was used as the ionization gas. Two microliters of the sample were injected using the pulsed splitless mode with an inlet temperature program: $60{ }^{\circ} \mathrm{C}$ for $0.1 \mathrm{~min}, 30^{\circ} \mathrm{C} /$ min until $280{ }^{\circ} \mathrm{C}$ and held for a final $20 \mathrm{~min}$. The GC oven program was as follows: initial $60{ }^{\circ} \mathrm{C}$ for $2 \mathrm{~min}, 30^{\circ} \mathrm{C} / \mathrm{min}$ until $150{ }^{\circ} \mathrm{C}, 2{ }^{\circ} \mathrm{C} / \mathrm{min}$ until $240{ }^{\circ} \mathrm{C}, 20^{\circ} \mathrm{C} / \mathrm{min}$ until $300^{\circ} \mathrm{C}$ and held for $5 \mathrm{~min}$. The temperature of the MS transfer line was held at $280^{\circ} \mathrm{C}$. The ion source and quadrupole temperatures were $150{ }^{\circ} \mathrm{C}$.

\subsection{Quality assurance and quality control}

One method blank was run for each batch of samples extracted and five method blanks were obtained in total for the 82 samples extracted. The mean absolute blank values of chemicals ranged from $0.03-5.2 \mathrm{pg}$ per sample. The method detection limits (MDLs) were derived from the mean field blank values plus three times the standard deviation $(\sigma)$. For compounds not present in the field blanks, instrumental detection limits (at a signal-to-noise ratio of three-to-one) were used instead. Using a mean sediment sample mass of $10 \mathrm{~g}$, the MDLs ranged from 0.1 to $27.7 \mathrm{pg} / \mathrm{g}$ (Tables S2 and S3, Supplementary material). The spike test recoveries were $123 \pm 27 \%$ for dicofol and $66 \pm 4 \%$ for $\alpha$-endosulfan. For the other 21 compounds, the recoveries ranged from 71 to $101 \%$. The surrogate recoveries ranged from $72 \%$ to $121 \%$ with a mean of 101 $\pm 14 \%$ for $\mathrm{HCH}-\mathrm{d}_{6}$, and from $67 \%$ to $117 \%$ with a mean oft $96 \pm 11 \%$ for trifluralin- $\mathrm{d}_{14}$. The recoveries were satisfactory, and no correction of analytical data was applied to the samples.

\section{Results and discussion}

\subsection{Concentrations of OCPS}

The detection frequencies of the 23 OCP compounds in the Y1 core (39 samples) and the Y2 core (43 samples) are provided in Tables S2 and S3 (Supplementary material) respectively. In the 39 samples of the Y1 core, the detection frequencies of 12 compounds ( $p, p^{\prime}$-DDE, $o, p$ '-DDD, $p, p^{\prime}$-DDD, o, $p^{\prime}$-DDT, $p, p^{\prime}$-DDT, $\alpha$-HCH, HCB, cis-chlordane, trans- chlordane, $\alpha$-endosulfan, pentachloroanisole and dicofol) were $100.0 \%$, 6 compounds $\left(o, p^{\prime}\right.$-DDE, $\beta$-HCH, $\gamma-\mathrm{HCH}$, trifluralin, chlorpyrifos and mirex) were between 87.1 and $97.4 \%$, and the other 5 compounds ( $\beta$ endosulfan, endosulfan-sulfate, quintozene, dacthal and methoxychlor) were lower than $87.1 \%$. In the 43 samples of the Y2 core, the detection frequencies of 7 compounds (o, $p^{\prime}$-DDT, $p, p^{\prime}$-DDT, $\beta$-HCH, $\gamma-\mathrm{HCH}, \mathrm{HCB}$, pentachloroanisole and trifluralin) were $100.0 \%, 10$ compounds (o, $p^{\prime}-$ DDE, $p, p^{\prime}$-DDE, $0, p^{\prime}$-DDD, $p, p^{\prime}$-DDD, $\alpha-\mathrm{HCH}$, cis-chlordane, transchlordane, $\alpha$-endosulfan, chlorpyrifos and dicofol) were between 67.4 and 97.7\%, and the other 6 compounds ( $\beta$-endosulfan, endosulfansulfate, quintozene, dacthal, methoxychlor and mirex) were lower than $67.4 \%$.

The descriptive statistics of the concentrations for the 23 OCP compounds are also summarized in Tables S2 and S3 (Supplementary material). In the Y1 core, dicofol was the most abundant individual compound, with average concentration of $391.5 \mathrm{pg} / \mathrm{g}$ (dry weight), followed by $p, p^{\prime}$-DDT (155.0 pg/g), o, $p^{\prime}$-DDT(148.9 pg/g) and $\mathrm{HCB}(126.3 \mathrm{pg} / \mathrm{g})$. For the total concentration of DDT isomers, the $\sum$ DDTs ranged from 283.3 to $1048.7 \mathrm{pg} / \mathrm{g}$ with an average of $477.9 \mathrm{pg} / \mathrm{g}$. For the $\mathrm{HCHs}$, the $\sum \mathrm{HCHs}$ ranged from 107.4 to $380.1 \mathrm{pg} / \mathrm{g}$ with an average of $179.4 \mathrm{pg} / \mathrm{g}$. In the Y2 core, $o, p^{\prime}$-DDT was the most abundant individual compound, with an average concentrations of $84.5 \mathrm{pg} / \mathrm{g}$, followed by $p, p^{\prime}$-DDT (83.1 pg/g), dicofol $(63.1 \mathrm{pg} / \mathrm{g})$ and HCB $(60.7 \mathrm{pg} / \mathrm{g})$. The $\sum$ DDTs ranged from 144.5 to $415.8 \mathrm{pg} / \mathrm{g}$ (230.8 pg/g on average), and $\sum \mathrm{HCHs}$ from 6.2 to $121.6 \mathrm{pg} / \mathrm{g}$ ( $37.0 \mathrm{pg} / \mathrm{g}$ on average).

As shown in Table 1, the $\sum$ DDTs and $\sum$ HCHs in the sediment cores from Yamzho Yumco Lake were one or two orders of magnitude lower than those reported in the developed areas (Zhao et al., 2009; Lu et al., 2012). Nevertheless, the $\sum$ DDTs and $\sum$ HCHs were close to the values of background areas, such as the Andes and Antarctica (Borghini et al., 2005; Klanova et al., 2008). In addition to DDTs and HCHs, some other compounds, such as mirex, chlorpyrifos and trifluranlin, were also detected in this study although little attention has been paid to them in previous reports. Generally, their concentrations were one or two orders of magnitude lower than those of the individual isomers of DDTs and HCHs (Tables S2 and S3, Supplementary material).

\section{2. $\sum D D T s$ and the composition in the sediment cores}

As shown in Fig. 2, the $\sum$ DDTs in the Y2 core shows a similar trend to that of $Y 1$, and the mean concentration differences between $Y 1$ and Y2 were found to be caused by the differences in their sedimentation rates. In the Y1 core, the $\sum$ DDTs started to increase in the 1950s, peaked in the 1970s, and then decreased in the 1980s. In the 1970s, OCPs, including DDTs, had been heavily used in agriculture around the word, especially in China and India (Voldner and Li, 1995). Correspondingly, the concentration peaks of DDTs in the cores were observed in the 1970s. The same occurrence has also been found in the ice cores of the TP (Wang et al., 2008). Since the global ban of DDTs in agriculture from the late 1970s, their concentration levels in the environment decreased greatly, even in low-altitude ecosystems (Chen et al., 2002). In this case, another concentration peak of the $\sum$ DDTs was observed at the end of the 1990s (Fig. 2), although it was not found in the ice cores (Wang et al., 2008). Since the agricultural application of DDTs

Table 1

$\sum$ DDTs and $\sum \mathrm{HCHs}$ in sediments from lakes worldwide.

\begin{tabular}{|c|c|c|c|}
\hline & Location & $\sum$ DDTs (ng/g) & $\sum \mathrm{HCHs}(\mathrm{ng} / \mathrm{g})$ \\
\hline \multirow[t]{5}{*}{ Background areas } & Yamzho Yumco Lake (this study) & $0.14-1.05$ & $0.01-0.38$ \\
\hline & Nam Co Lake in Tibet (Cheng et al., 2014) & $0.4-4.1$ & $0.7-2.8$ \\
\hline & Baikal Lake in Russia (Iwata et al., 1995) & $0.01-2.7$ & $0.02-0.12$ \\
\hline & Mountain Andes Lakes (Borghini et al., 2005) & $0.019-4.1$ & $<0.005-0.23$ \\
\hline & Phormidium Lake in Antarctica (Klanova et al., 2008) & $0.19-1.15$ & $0.14-0.76$ \\
\hline \multirow[t]{2}{*}{ Developed areas } & Taihu Lake in China (Zhao et al., 2009) & $0.25-375$ & $0.07-5.75$ \\
\hline & Poyang Lake in China (Lu et al., 2012) & $14.42-82.87$ & $0.54-6.94$ \\
\hline
\end{tabular}




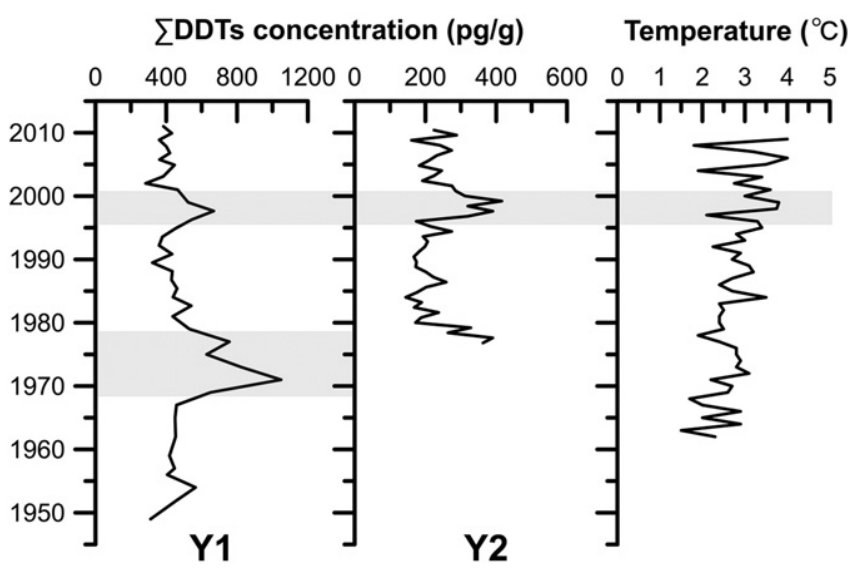

Fig. 2. $\sum$ DDTs in the cores and air temperature along the same time series.

was banned in China in 1983 and in India in 1989, such a concentration peak should not originate from the heavy usage of DDTs. Although DDTs have been still used for health services, for example malaria/mosquito control (Bouwman et al., 2011), the amounts of usage emissions were two or more orders of magnitude lower than those in the 1970s.

In the sediment cores from the alpine lakes, a peak in the legacy POPs at the end of the 1990s was also observed, which was attributed to the release of POPs from melting glaciers due to global warming (Bettinetti et al., 2011; Schmid et al., 2011). In the TP, a significant release of POPs from melting glaciers was also found from approximately 2000 (Li et al., 2017b). In the area of Yamzho Yumco Lake, the monitoring data show that a rapid increase of the average air temperature was observed at the end of the 1990s (Fig. 2) (Laba et al., 2012), which is one of the performance indicators of global warming. Comparably, the concentration peak of the $\sum$ DDTs at the end of the 1990s could be understood as the addition of DDTs released from melting glaciers or the cryosphere. On the other hand, some reports suggest that the revolatilization of POPs from sea water possibly increased their level in air due to global warming (Ma et al., 2011), which might influence the air deposition in the TP. Nevertheless, it has been clarified in our previous literature that the re-volatilization of POPs from sea water did not yield great increase on the level of POPs in TP (Li et al., 2017b). Although there are many others environmental factors, the relationship between the temperature increase and concentration peak in Fig. 2 is obvious. These other factors contribute to the peaks, but they are not the main source.

Although DDTs are usually persistent in the environment, their isomeric ratios still change with chemical weathering as well as biological transformation (Morrison et al., 2000; Feng et al., 2003) that could be archived in the lake sediments. $o, p^{\prime}$-DDT and $p, p^{\prime}$-DDT in the environment can be degraded into DDD under anaerobic conditions and into DDE under aerobic conditions (Morrison et al., 2000). Speculatively, DDTs would be preferentially transformed into DDE in the surface sediments and into DDD in the deep sediments. The ratios of DDD/ $\sum$ DDTs or DDE/ $\sum$ DDTs have been used to identify the transformation process of DDTs (Chen et al., 2017). In this case, the specific isomeric ratios were also used to determine the transformation or degradation of DDTs in the sediment cores. As shown in Fig. 3, there was almost no difference for the values of (DDD + DDE)/ $\sum$ DDTs between the Y1 and Y2 cores. Interestingly, most values predominantly ranged from 0.3 to 0.4 , which was constant from the deep to the surface sediments in the cores. Such a result indicates that the degradation or transformation of DDTs in deep sediments was not greater than that at the surface over time. Otherwise, the deep sediments should show higher values of (DDD + DDE) $/ \sum$ DDTs than that found in the surface, since the DDTs in the deep sediments were deposited several decades earlier than those at the surface. In the environmental conditions of the TP, microbiological activity is very weak due to the low temperature (Yuan et al., 2014a).

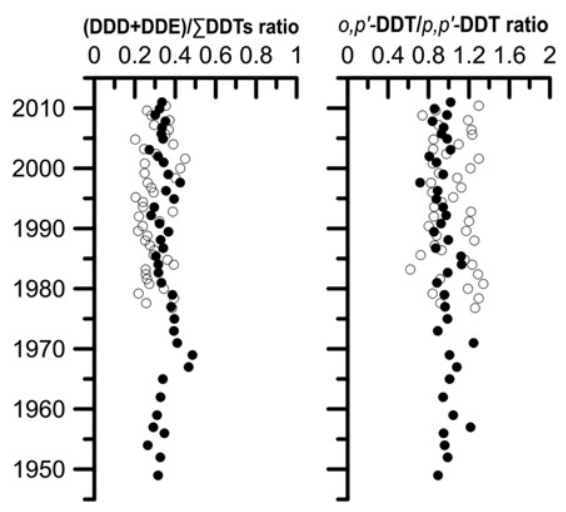

Fig. 3. (DDD + DDE) $/ \sum D D T s$ and $o, p^{\prime}-\mathrm{DDT} / p, p^{\prime}$-DDT ratios in the core (solid circles for $\mathrm{Y} 1$ and hollow circles for Y2).

In addition, most of the lakes in the TP are saltwater lakes, which may also limit the activity of terrestrial microorganisms. Reasonably, the degradation or transformation of DDTs would be very weak as observed. This ensured that the detected DDTs in the cores could really represent the historical occurrence of DDTs in Yamzho Yumco Lake.

Without the influence of degradation in sediments over time, the constant values of (DDD + DDE)/ $\sum$ DDTs in the sediment cores indicates that the compositions of DDTs were almost the same as when they were deposited in the TP. It is well known that POPs were deposited in the TP through LRAT from the source areas (Wang et al., 2012; Gong et al., 2015; Yuan et al., 2014b, 2015). Although the source compositions of DDTs were not uniform in different time periods, the weathering process during LRAT caused the complex source compositions to be uniform when they reached the TP. Analogously, the function of the weathering of the DDTs during LRAT was similar to that of river water, which grinds different stones from the source area into uniform sand in the estuary. Consequently, the values of (DDD + DDE)/ $\sum$ DDTs were constant in the different deposition periods, such as the period of heavy usage in the 1970s, the banned usage period after the 1980s, and the glacier or cryosphere melting period at the end of the 1990s.

In addition, the ratio values of $o, p^{\prime}$-DDT $/ p, p^{\prime}$-DDT were also found to be uniform in the cores (Fig. 3), and the values predominantly ranged from 0.9 to 1.1 which are much higher than those of technical DDTs (0.2-0.3) (Qiu and Zhu, 2010). Although there was a slight difference in the degrading rates in the environment between $p, p^{\prime}$-DDT and $o, p^{\prime}$ DDT, previous studies have confirmed that the values of $o, p^{\prime}$-DDT $/ p, p^{\prime}-$ DDT in the environment have not been greatly influenced by the environmental weathering process (Qiu and Zhu, 2010). Nevertheless, the addition of dicofol residues could greatly change the values of $o, p^{\prime}-$ $\mathrm{DDT} / p, p^{\prime}$-DDT in the environment. Both of $o, p^{\prime}$-DDT and $p, p^{\prime}$-DDT were by-products of the production of technical dicofol, and the value of $0, p^{\prime}$-DDT $/ p, p^{\prime}$-DDT was approximately 7 on average (Qiu et al., 2005). Thus, dicofol residues could increase the mentioned ratio values, which could then well interpret the higher values of $o, p^{\prime}$-DDT $/ p, p^{\prime}$-DDT in this case. In fact, the mean concentration of dicofol was higher than the other 22 individual compounds in the Y1 core. The values of $o, p^{\prime}$ $\mathrm{DDT} / p, p^{\prime}$-DDT observed in Antarctica were also much higher than those of technical DDTs (Kallenborn et al., 2013). Consequently, the ratios of $o, p^{\prime}$-DDT to $p, p^{\prime}$-DDT being deposited in the TP in different time periods were relatively constant, although the addition of dicofol into the source areas greatly increased the ratio values of $o, p^{\prime}-\mathrm{DDT} / p, p^{\prime}-$ DDT during the process of LRAT.

\section{3. $\sum H C H s$ and the composition}

For the $\sum \mathrm{HCHs}$ in cores, the historic trends are the same as those of the $\sum$ DDTs (Fig. 4). The significantly high level of the $\sum$ HCHs in the 1970 s reflect their heavy and continuous usage around the world, 
$\sum \mathrm{HCH}$ concentration $(\mathbf{p g} / \mathbf{g}) \quad \beta-\mathrm{HCH} / \Sigma \mathrm{HCHs}$ ratio $\gamma-\mathrm{HCH} / \Sigma \mathrm{HCH}$ ratio

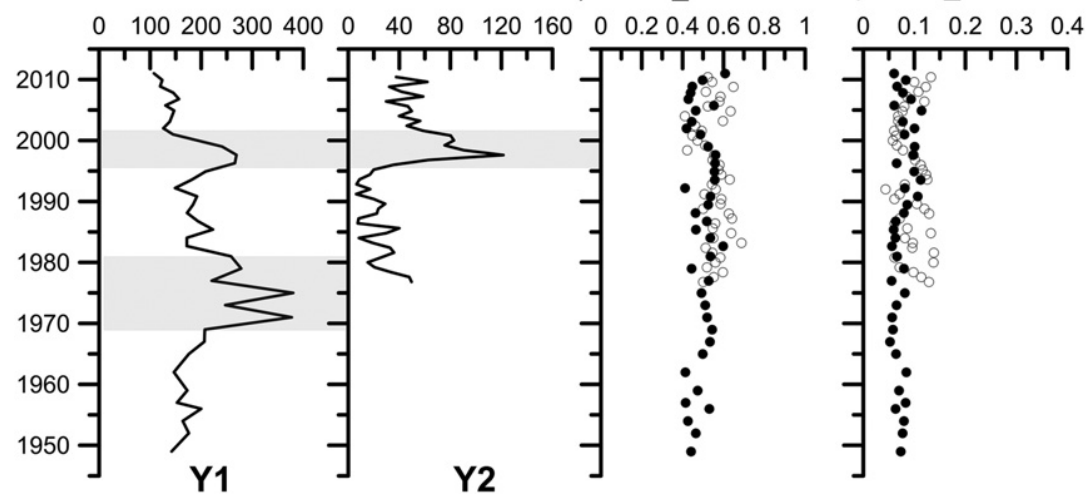

Fig. 4. $\sum \mathrm{HCHs}$ concentrations, $\beta-\mathrm{HCH} / \sum \mathrm{HCHs}$ and $\gamma-\mathrm{HCH} / \sum \mathrm{HCHs}$ ratios in the core (solid circles for $\mathrm{Y} 1$ and hollow circles for $\mathrm{Y} 2$ ).

especially in China and Southeast Asia at that time (Voldner and Li, 1995). Subsequently, the concentrations of the $\sum \mathrm{HCH}$ decreased from the early 1980s since the global ban of the use of HCHs in agriculture. In addition, concentration peaks at the end of the 1990s were also observed, which was reasonably understood as the addition of HCHs released from the melting glaciers or the cryosphere as discussed in the section above.

In many cases, the values of $\beta-\mathrm{HCH} / \sum \mathrm{HCHs}$ were applied to determine the degree of $\mathrm{HCH}$ weathering in the environment, since $\beta-\mathrm{HCH}$ shows higher stability than $\alpha-\mathrm{HCH}$ and $\gamma-\mathrm{HCH}$ (Niu et al., 2013; Walker et al., 1999). In technical products, the values of $\beta-\mathrm{HCH} /$ $\sum$ HCHs were in the range of 0.05-0.12 (Willett et al., 1998). In the environment, $\alpha-\mathrm{HCH}$ and $\gamma-\mathrm{HCH}$ can be degraded or transformed into $\beta$ $\mathrm{HCH}$ (Walker et al., 1999). In this case, the values of $\beta-\mathrm{HCH} / \sum \mathrm{HCHs}$ were constant at approximately 0.5 from the deep to the surface sediments. The high values of $\beta-\mathrm{HCH} / \sum \mathrm{HCH}$ indicate that the $\mathrm{HCHs}$ in the sediments had undergone rather strong weathering before being deposited in the sediments. Imaginably, HCHs should be greatly weathered during the process of LRAT from the source areas to the TP. As a result, the values of $\beta-\mathrm{HCH} / \sum \mathrm{HCH}$ in the cores were much higher than those of the technical products. As discussed for the DDTs in the section above, the process of LRAT caused the composition of the $\mathrm{HCH}$ s to be uniform before being deposited in the TP in different periods. At the same time, the constant values of $\beta-\mathrm{HCH} / \sum \mathrm{HCH}$ also suggests that the degradation and transformation of $\mathrm{HCHs}$ in the sediments of Yamzho Yumco Lake seldom occurs.

Since the ban of HCHs in the 1980s, lindane has been used as a replacement (Walker et al., 1999; Feng et al., 2003). In technical lindane, the percentage of $\gamma-\mathrm{HCH}$ is approximately 99\% (Walker et al., 1999).

\section{Concentration $(\mathrm{pg} / \mathrm{g})$}

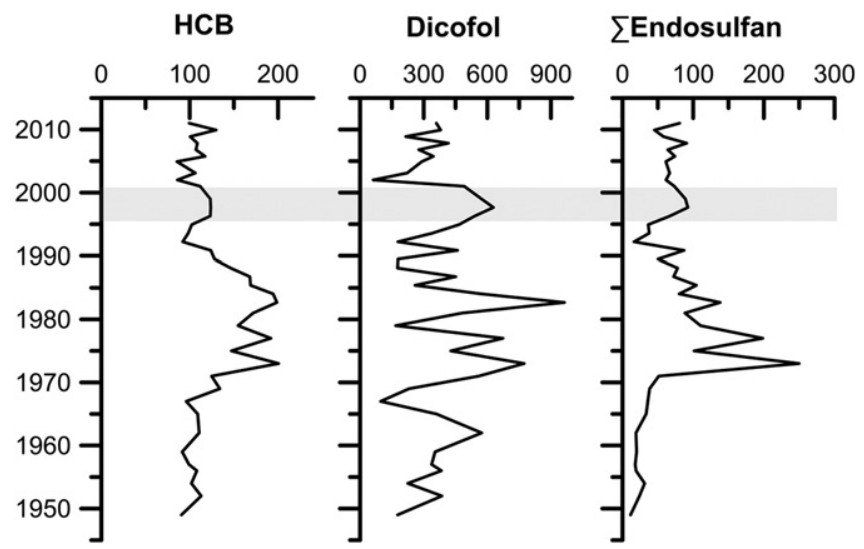

Fig. 5. Concentrations of $\mathrm{HCB}$, dicofol and endosulfan in the Y1 core.
Nevertheless, the values of $\gamma-\mathrm{HCH} / \sum \mathrm{HCH}$ in the cores did not increase, which indicates that the composition deposited in the TP was not significantly influenced by the proportions of $\alpha-\mathrm{HCH}, \beta-\mathrm{HCH}$ and $\gamma-\mathrm{HCH}$ in the remote sources. As discussed above, the great weathering during LRAT has caused the composition of the $\mathrm{HCHs}$ to be uniform.

\subsection{HCB, dicofol and endosulfan}

In addition to the DDTs and HCHs, some other OCPs were detected at relativelu high concentrations with $>90 \%$ detection frequencies, including $\mathrm{HCB}$, dicofol and endosulfan. In the sediments, the concentrations of these compounds and those of the individual isomers of DDTs and HCHs were of the same order of magnitude (Tables S2 and S3, Supplementary material). Nevertheless, their concentrations were close to their values in the background areas of the world, such as the Arctic (Li et al., 2015). The concentrations of these compounds in the Y2 core showed a similar trend to those found at Y1, and the mean concentration differences between $\mathrm{Y} 1$ and $\mathrm{Y} 2$ are considered to be caused by the difference in the sedimentation rate. Therefore, we chose the Y1 core as the representative to maintain clarity. As shown in Fig. 5, the historical trend of their concentrations in the Y1 core was similar to those of the DDTs and HCHs. The concentration peaks were also observed to be in the period of heavy usage and in the period of glacier or cryosphere melting.

Although the total concentrations of $\alpha$-endosulfan and $\beta$-endosulfan were relatively high among the 23 compounds, $\alpha$-endosulfan was dominant and accounted for $81 \%$ to $99 \%$ of $\sum$ endosulfan ( $96 \%$ on average). The same occurrence was also found in other background areas, which was attributed to the difference of the transportation ability between $\alpha$-endosulfan and $\beta$-endosulfan during LRAT (Baek et al., 2011). In this study, endosulfan-sulfate was almost never detected in the sediments, although it has been frequently detected in other regions due to microbial metabolism (Liu et al., 2010). This result indicates that the microbial transformation from $\alpha$-endosulfan or $\beta$-endosulfan to endosulfansulfate was very weak in the unique environment of the TP. Comprehensively, the chemical and biological transformation in sediments from lakes in the TP is very weak, which was confirmed not only by the lack of endosulfan-sulfate in the sediments but also by the constant ratio values of $(\mathrm{DDD}+\mathrm{DDE}) / \sum \mathrm{DDT}$ and $\beta-\mathrm{HCH} / \sum \mathrm{HCHs}$.

\subsection{Chlordane, mirex, chlorpyrifos and trifluralin}

As shown in Fig. 6, the concentrations of chlordane, mirex, chlorpyrifos and trifluralin in the Y1 core were one order of magnitude lower than those of the other compounds mentioned above. Due to the small amount of their usage in history, little attention has been paid to them, especially in the TP. Nevertheless, the detection frequency for them was relatively high in this case (Tables S2 and S3, Supplementary material), which indicates that they were really transported into the TP 


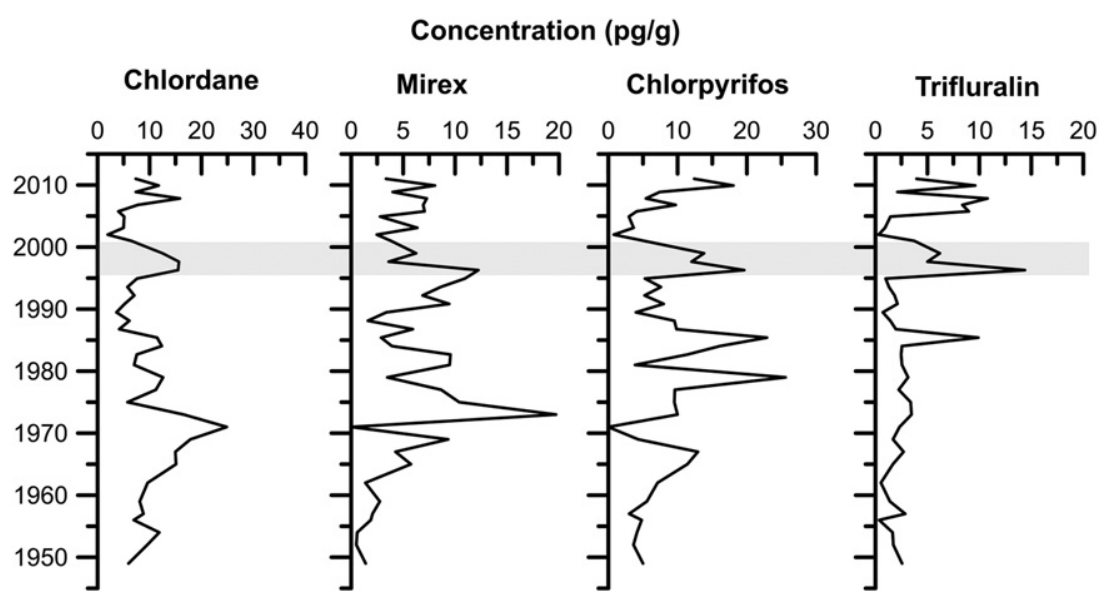

Fig. 6. Concentrations of chlordane, mirex, chlorpyrifos and trifluralin in the Y1 core.

and then deposited in the lake. Since the history of their usage is different, the times corresponding to their concentration peaks in the cores are different from each other (Fig. 6). The OCPs in the sediments from lakes had undergone complicated weathering before their deposition, and sediment disturbance has made the situation more complex. Substances in very low concentrations could be influenced by so many factors. However, the concentration peaks due to glacial release at end of the 1990s are clearly observed in the core, which is enough to verify our hypothesis. In addition, recent research revealed that chlorpyrifos and trifluralin are potentially harmful compounds (Bozari and Aksakal, 2013; Ventura et al., 2016), although they had been considered to be safe for several decades.

At the same time, the value of $\mathrm{TC} /(\mathrm{TC}+\mathrm{CC})$ is usually used to estimate the degree of degradation of chlordane, and a lower value usually corresponded to a higher degree of degradation (Bidleman et al., 2015). In this case, the values of TC/(TC + CC) ranged from 0.35 to 0.44 (Fig. S1, Supplementary material), which is close to that found in the surface soils of the TP (0.37-0.41) (Yuan et al., 2015) and in the Alps (0.43) (Tremolada et al., 2008). In technical chlordane, the value of TC/(TC + CC) is between 0.54 and 0.61 (Yuan et al., 2015). In environment, TC shows a relatively higher photochemical reactivity than CC, and thus TC would be preferentially removed from the environment (Becker et al., 2012). On the other hand, the values of TC/(TC + CC) were constant from the deep to the surface sediments in the cores (Fig. S1), which indicates that the transformation of chlordane in the sediments over time is negligible. Once again, such a result supports the hypothesis that OCPs in sediment cores can effectively represent their characteristics at the time of deposition without further degradation or transformation in the sediments.

\section{Conclusions}

Two sediment cores from Yamzho Yumco Lake were drilled and dated with high resolution. The deposition history of OCPs was reconstructed based on the analysis of 23 OCPs in the cores. The most abundant compound in the Y1 core was dicofol with an average concentration of $391.5 \mathrm{pg} / \mathrm{g}$, followed by $p, p^{\prime}$-DDT (155.0 pg/g), o, $p^{\prime}$ DDT(148.9 pg/g) and HCB (126.3 pg/g). The most abundant compound in the Y2 core was $o, p^{\prime}$-DDT with an average concentration of $84.5 \mathrm{pg} / \mathrm{g}$, followed by $p, p^{\prime}$-DDT $(83.1 \mathrm{pg} / \mathrm{g})$, dicofol $(63.1 \mathrm{pg} / \mathrm{g})$ and $\mathrm{HCB}$ $(60.7 \mathrm{pg} / \mathrm{g})$. In the sediment cores, concentration peaks in the times of heavy usage were observed for several OCPs, such as DDTs, HCHs, $\mathrm{HCB}$, dicofol, endosulfan, chlordane, mirex, chlorpyrifos and trifluralin. Furthermore, the addition of OCPs released from glacial melting was found to be recorded in the cores, which resulted in a significant concentration increase at the end of the 1990s. By the determination of the isomeric ratios, the transformation or degradation of OCPs in the sediment cores was found to be limited over time. Such a result ensures that the detected OCPs in the sediments could effectively represent their characteristics at the time of deposition. In other words, environmental self-purification is very weak in the TP, in which case the OCPs would last longer in the TP than in other regions, which is now first reported in the TP to preserve the history of POPs using sedimentary records. Under ongoing global warming, the archived OCPs in glaciers or the cryosphere will be continuously released. In the next decades, the fragile ecological environment of the TP will still be threatened not only by the residual POPs in the sediments or soils but also by the "secondary source" of POPs released from the melting cryosphere. Our research provides insight into the influence of global warming and glacial melting on the environment of the TP, and further work to gain a better understanding of the environmental processes of the POPs in the TP is ongoing.

\section{Acknowledgments}

This study was financially supported by the Fundamental Research Funds for the Central Universities (2652016073, 2652016074, 2652017239, 2652017240) and Innovation Group of Environmental Geochemistry (512039861-B1); and State Key Laboratory of Biogeology and Environmental Geology (GBL2135, GBL21405). We thank the members of the Rongmanan Geological Survey Project of CUGB for their help in collecting the samples. Dr. ZY Xie of HZG Centre for Materials and Coastal Research GmbH, Germany and Dr. Fang of IC of CAS are also gratefully acknowledged for assistance with the analysis.

\section{Appendix A. Supplementary data}

Table S1, the Information of sampling sites; Table S2, the statistics of OCPs in Y1 core; Table S3, the statistics of OCPs in Y2 core; Fig. S1, TC/(TC $+\mathrm{CC}$ ) ratios in the core. Supplementary data associated with this article can be found in the online version, at https://doi.org/10.1016/j. scitotenv.2017.09.282.

\section{References}

Arellano, L., Fernandez, P., Tatosova, J., Stuchlik, E., Grimalt, J.O., 2011. Long-range transported atmospheric pollutants in snowpacks accumulated at different altitudes in the Tatra Mountains (Slovakia). Environ. Sci. Technol. 45, 9268-9275.

Baek, S.Y., Choi, S.D., Chang, Y.S., 2011. Three-year atmospheric monitoring of organochlorine pesticides and polychlorinated biphenyls in Polar regions and the South Pacific. Environ. Sci. Technol. 45, 4475-4482.

Becker, S., Halsall, C.J., Tych, W., Kallenborn, R., Schlabach, M., Mano, S., 2012. Changing sources and environmental factors reduce the rates of decline of organochlorine pesticides in the Arctic atmosphere. Atmos. Chem. Phys. 12, 4033-4044.

Bettinetti, R., Galassi, S., Guilizzoni, P., Quadroni, S., 2011. Sediment analysis to support the recent glacial origin of DDT pollution in Lake Iseo (Northern Italy). Chemosphere 85, 163-169. 
Bidleman, T.F., Jantunen, L.M., Hung, H., Ma, J., Stern, G.A., Rosenberg, B., Racine, J., 2015. Annual cycles of organochlorine pesticide enantiomers in Arctic air suggest changing sources and pathways. Atmos. Chem. Phys. 15, 1411-1420.

Bogdal, C., Schmid, P., Zennegg, M., Anselmetti, F.S., Scheringer, M., Hungerbuehler, K. 2009. Blast from the past: Melting glaciers as a relevant source for persistent organic pollutants. Environ. Sci. Technol. 43, 8173-8177.

Borghini, F., Grimalt, J.O., Sanchez-Hernandez, J.C., Barra, R., Garcia, C.J.T., Focardi, S., 2005. Organochlorine compounds in soils and sediments of the mountain Andean Lakes. Environ. Pollut. 136, 253-266.

Bouwman, H., van den Berg, H., Kylin, H., 2011. DDT and Malaria prevention: addressing the paradox. Environ. Health Perspect. 119, 744-747.

Bozari, S., Aksakal, O., 2013. Application of random amplified polymorphic DNA (RAPD) to detect genotoxic effect of trifluralin on maize (Zea mays). Drug Chem. Toxicol. 36 163-169.

Chen, J.F., Xia, X.M., Ye, X.R., Jin, H.Y., 2002. Marine organic pollution history in the Changjiang Estuary and Zhejiang coastal area - HCHs and DDTs stratigraphical records. Mar. Pollut. Bull. 45, 391-396.

Chen, L.G., Feng, Q.H., He, Q.S., Huang, Y.M., Zhang, Y., Jiang, G., Zhao, W., Gao, B., Lin, K $\mathrm{Xu}$, Z.C. 2017. Sources, atmospheric transport and deposition mechanism of organochlorine pesticides in soils of the Tibetan Plateau. Sci. Total Environ. 577, 405-412.

Cheng, H., Lin, T., Zhang, G., Liu, G., Zhang, W., Qi, S., Jones, K.C., Zhang, X., 2014. DDTs and HCHs in sediment cores from the Tibetan Plateau. Chemosphere 94, 183-189.

Feng, K., Yu, B.Y., Ge, D.M., Wong, M.H., Wang, X.C., Cao, Z.H., 2003. Organo-chlorine pesticide (DDT and $\mathrm{HCH}$ ) residues in the Taihu Lake region and its movement in soilwater system I. Field survey of DDT and $\mathrm{HCH}$ residues in ecosystem of the region. Chemosphere 50, 683-687.

Gong, P., Wang, X.P., Xue, Y.G., Sheng, J.J., Gao, S.P., Tian, L.D., Yao, T.D., 2015. Influence of atmospheric circulation on the long-range transport of organochlorine pesticides to the western Tibetan Plateau. AtmRe 166, 157-164.

Guzzella, L., Salerno, F., Freppaz, M., Roscioli, C., Pisanello, F., Poma, G., 2016. POP and PAH contamination in the southern slopes of Mt. Everest (Himalaya, Nepal): long-range atmospheric transport, glacier shrinkage, or local impact of tourism? Sci. Total Environ. 544, 382-390.

Iwata, H., Tanabe, S., Ueda, K., Tatsukawa, R., 1995. Persistent organochlorine residues in air, water, sediments, and soils from the Lake Baikal region, Russia. Environ. Sci. Technol. 29, 792-801.

Kallenborn, R., Breivik, K., Eckhardt, S., Lunder, C.R., Mano, S., Schlabach, M., Stohl, A 2013. Long-term monitoring of persistent organic pollutants (POPs) at the Norwegian Troll station in Dronning Maud Land, Antarctica. Atmos. Chem. Phys. 13, 6983-6992.

Khairy, M.A., Luek, J.L., Dickhut, R., Lohmann, R., 2016. Levels, sources and chemical fate of persistent organic pollutants in the atmosphere and snow along the western Antarctic Peninsula. Environ. Pollut. 216, 304-313.

Klanova, J., Matykiewiczova, N., Macka, Z., Prosek, P., Laska, K., Klan, P., 2008. Persistent organic pollutants in soils and sediments from James ROSS Island, Antarctica. Environ. Pollut. 152, 416-423.

Laba, Z., Ci, Z., La, B., Deji, Y., 2012. Characteristics of climate change at Yamdrog Yumtso Lake during the 1971-2009. J. Tibet Univ. 2, 15-19 (in Chinese with English abstract).

Lafreniere, M.J., Blais, J.M., Sharp, M.J., Schindler, D.W., 2006. Organochlorine pesticide and polychlorinated biphenyl concentrations in snow, snowmelt, and runoff at Bow Lake, Alberta. Environ. Sci. Technol. 40, 4909-4915.

Li, L., Liu, J.G., Hu, J.X., 2015. Global Inventory, long-range transport and environmental distribution of dicofol. Environ. Sci. Technol. 49, 212-222.

Li, C., Huo, S., Yu, Z., Xi, B., Yeager, K.M., He, Z., Ma, C., Zhang, J., Wu, F., 2017a. National investigation of semi-volatile organic compounds (PAHs, OCPs, and PCBs) in lake sediments of China: occurrence, spatial variation and risk assessment. Sci. Total Environ. $579,325-336$

Li, J., Yuan, G.L., Wu, M.Z., Sun, Y., Han, P., Wang, G.H., 2017b. Evidence for persistent organic pollutants released from melting glacier in the central Tibetan Plateau, China. Environ. Pollut. 220, 178-185.

Liu, J., Zhou, L., Shi, L., Shan, Z., Zhou, H., Lv, F., Chen, G., 2010. Degradation of endosulfan and endosulfan sulfate in soils. Acta Sci. Circumst. 30, 2484-2490.

Lu, M., Zeng, D.C., Liao, Y., Tong, B., 2012. Distribution and characterization of organochlorine pesticides and polycyclic aromatic hydrocarbons in surface sediment from Poyang Lake, China. Sci. Total Environ. 433, 491-497.

Ma, J.M., Hung, H.L., Tian, C., Kallenborn, R., 2011. Revolatilization of persistent organic pollutants in the Arctic induced by climate change. Nat. Clim. Chang. 1, 255-260.

Mangano, M.C., Sara, G., Corsolini, S., 2017. Monitoring of persistent organic pollutants in the Polar regions: knowledge gaps \& gluts through evidence mapping. Chemosphere $172,37-45$.

Morrison, D.E., Robertson, B.K., Alexander, M., 2000. Bioavailability to earthworms of aged DDT, DDE, DDD, and dieldrin in soil. Environ. Sci. Technol. 34, 709-713.
Niu, L., Xu, C., Yao, Y., Liu, K., Yang, F., Tang, M., Liu, W., 2013. Status, Influences and risk assessment of hexachlorocyclohexanes in agricultural soils across China. Environ. Sci. Technol. 47, 12140-12147.

Pavlova, P.A., Zennegg, M., Anselmetti, F.S., Schmid, P., Bogdal, C., Steinlin, C., Jaggi, M., Schwikowski, M., 2016. Release of PCBs from Silvretta glacier (Switzerland) investigated in lake sediments and meltwater. Environ. Sci. Pollut. Res. 23, 10308-10316.

Qiu, X.H., Zhu, T., 2010. Using the $o, p^{\prime}$-DDT/p, $p^{\prime}$-DDT ratio to identify DDT sources in China. Chemosphere 81, 1033-1038.

Qiu, X.H., Zhu, T., Yao, B., Hu, J.X., Hu, S.W., 2005. Contribution of dicofol to the current DDT pollution in China. Environ. Sci. Technol. 39, 4385-4390.

Schmid, P., Bogdal, C., Bluethgen, N., Anselmetti, F.S., Zwyssig, A., Hungerbuehler, K., 2011. The missing piece: Sediment records in remote mountain lakes confirm glaciers being secondary sources of persistent organic pollutants. Environ. Sci. Technol. 45, 203-208.

Shen, H., Huang, Y., Wang, R., Zhu, D., Li, W., Shen, G., Wang, B., Zhang, Y., Chen, Y., Lu, Y. Chen, H., Li, T., Sun, K., Li, B., Liu, W., Liu, J., Tao, S., 2013. Global atmospheric emissions of polycyclic aromatic hydrocarbons from 1960 to 2008 and future predictions. Environ. Sci. Technol. 47, 6415-6424.

Sun, Y., Yuan, G.L., Li, J., Li, J.C., Wang, G.H., 2015. Polybrominated diphenyl ethers in surface soils near the Changwengluozha Glacier of Central Tibetan Plateau, China. Sci. Total Environ. 511, 399-406.

Tremolada, P. Villa, S, Bazzarin, P. Bizzotto, E Comolli, R, Vighi, M, 2008. POPs in mountain soils from the Alps and Andes: Suggestions for a 'precipitation effect' on altitudinal gradients. Water Air Soil Pollut. 188, 93-109.

Ventura, C., Nieto, M.R.R., Bourguignon, N., Lux-Lantos, V., Rodriguez, H., Cao, G., Randi, A., Cocca, C., Nunez, M., 2016. Pesticide chlorpyrifos acts as an endocrine disruptor in adult rats causing changes in mammary gland and hormonal balance. J. Steroid Biochem. Mol. Biol. 156, 1-9.

Voldner, E.C., Li, Y.F., 1995. Global usage of selected persistent organochlorines. Sci. Total Environ. 160-61, 201-210.

Walker, K., Vallero, D.A., Lewis, R.G., 1999. Factors influencing the distribution of lindane and other hexachlorocyclohexanes in the environment. Environ. Sci. Technol. 33, 4373-4378.

Wang, X.P., Xu, B.Q., Kang, S.C., Cong, Z.Y., Yao, T.D., 2008. The historical residue trends of DDT, hexachlorocyclohexanes and polycyclic aromatic hydrocarbons in an ice core from Mt. Everest, central Himalayas, China. Atmos. Environ. 42, 6699-6709.

Wang, X.P., Sheng, J.J., Gong, P., Xue, Y.G., Yao, T.D., Jones, K.C., 2012. Persistent organic pollutants in the Tibetan surface soil: spatial distribution, air-soil exchange and implications for global cycling. Environ. Pollut. 170, 145-151.

Wang, X.P., Gong, P., Wang, C., Ren, J., Yao, T., 2016. A review of current knowledge and future prospects regarding persistent organic pollutants over the Tibetan Plateau. Sci. Total Environ. 573, 139-154.

Wania, F., Westgate, J.N., 2008. On the mechanism of mountain cold-trapping of organic chemicals. Environ. Sci. Technol. 42, 9092-9098.

Willett, K.L., Ulrich, E.M., Hites, R.A., 1998. Differential toxicity and environmental fates of hexachlorocyclohexane isomers. Environ. Sci. Technol. 32, 2197-2207.

Yao, T., Pu, J., Lu, A., Wang, Y., Yu, W., 2007. Recent glacial retreat and its impact on hydrological processes on the Tibetan Plateau, China, and sorrounding regions. Arct. Antarct. Alp. Res. 39, 642-650.

Yu, C.Q., Zhang, Y.J., Claus, H., Zeng, R., Zhang, X.Z., Wang, J.S., 2012. Ecological and environmental issues faced by a developing Tibet. Environ. Sci. Technol. 46, 1979-1980.

Yuan, G.L., Sun, Y., Qin, J.X., Li, J., Wang, G.H., 2014a. Chiral signature of alpha-HCH and o,p '-DDT in the soil and grass of the Central Tibetan Plateau, China. Sci. Total Environ. 500, 147-154.

Yuan, G.L., Qin, J.X., Lang, X.X., Li, J., Wang, G.H., 2014b. Factors influencing the accumulation of organochlorine pesticides in the surface soil across the Central Tibetan Plateau, China. Environ. Sci. Processes Impacts 16, 1022-1028.

Yuan, G.L., Wu, L.J., Sun, Y., Li, J., Li, J.C., Wang, G.H., 2015. Polycyclic aromatic hydrocarbons in soils of the Central Tibetan Plateau, China: distribution, sources, transport and contribution in global cycling. Environ. Pollut. 203, 137-144.

Yuan, H.Z., Liu, E.F., Zhang, E.L., Luo, W.L., Chen, L., Wang, C., Lin, Q., 2017. Historical records and sources of polycyclic aromatic hydrocarbons (PAHs) and organochlorine pesticides (OCPs) in sediment from a representative plateau lake, China. Chemosphere 173, 78-88.

Zaharescu, D.G., Hooda, P.S., Burghelea, C.I., Polyakov, V., Palanca-Soler, A., 2016. Climate change enhances the mobilisation of naturally occurring metals in high altitude. Sci. Total Environ. 560, 73-81.

Zhao, Z., Zhang, L., Wu, J., Fan, C., 2009. Distribution and bioaccumulation of organochlorine pesticides in surface sediments and benthic organisms from Taihu Lake, China. Chemosphere 77, 1191-1198. 